\title{
Dorothea Rockburne and Max Dehn at Black Mountain College
}

\author{
David Peifer
}

\author{
Communicated by Thomas Garrity
}

ABSTRACT. The artist Dorothea Rockburne was inspired by the mathematician Max Dehn while a student at Black Mountain College.

Dorothea Rockburne is a New York based artist whose paintings are inspired by her fascination with mathematics. Over her more than fifty years as a successful exhibiting artist, Rockburne has won many awards for her work, including the 1999 American Academy of Arts and Letters Jimmy Ernst Lifetime Achievement Award in Art and the 2009 National Academy Museum and School of Fine Arts Lifetime Achievement Award. A major retrospective, "Dorothea Rockburne: In My Mind's Eye," held in 2012 at the Parrish Art Museum, exhibited works spanning her career, including works from her Pascal series and paintings inspired by her reading of Poincaré. A multi-gallery exhibition at the Museum of Modern Art in 2014, Dorothea Rockburne: Drawing Which Makes Itself, included some of her earliest works from her Set Theory series.

The catalyst of Rockburne's interest in mathematics came during the first two years of her undergraduate education. In 1950, at age 17, Rockburne left her home in Montreal, Canada, to study painting at Black Mountain College (BMC),

David Peifer is professor of mathematics at the University of North Carolina at Asheville. His email address is dpei fer@unca.edu.

For permission to reprint this article, please contact: reprint-permission@ams.org.

DOI: http://dx.doi.org/10.1090/noti1599

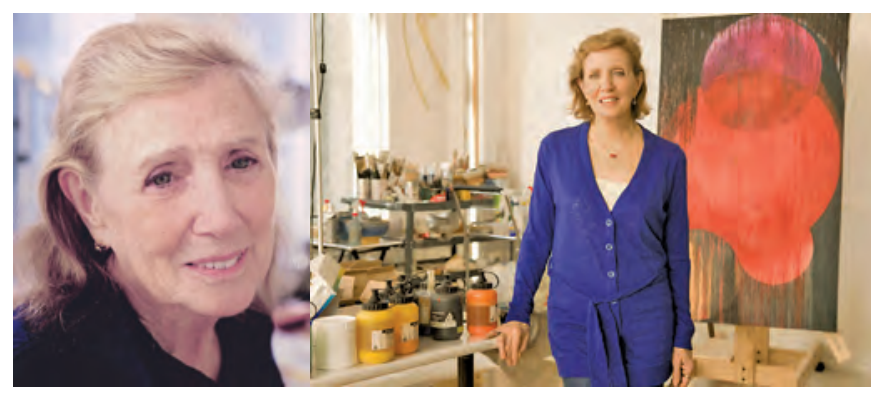

Figure 1. Dorothea Rockburne is a distinguished artist with a fascination for mathematics. Rockburne in 2014, photo by Zia O'Hara, (on left) and in her New York studio in 2009 (on right).

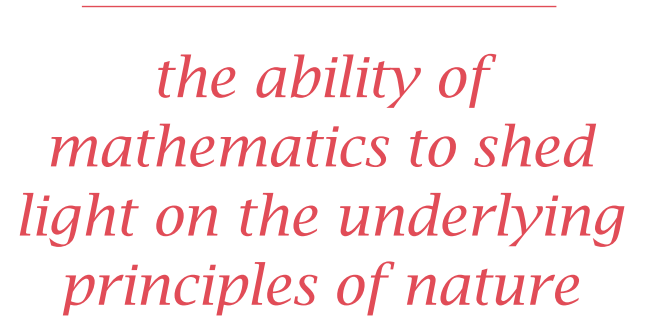

an experimental liberal arts college with an emphasis on the arts (see sidebar).

In 1945, the BMC faculty was joined by the German refugee mathematician Max Dehn. Dehn taught mathematics, philosophy, Greek, and Latin. He and his wife lived on the top floor in a small house on campus. Like most of the faculty, the Dehns ate their meals in the dining hall and participated in the social life on campus. On Sundays, when meals were not provided, Dehn and his wife frequently invited students to their home for dinner. Dehn was well known for taking faculty, students, and visitors on long hikes into the surrounding mountains in search of local wildflowers.

Before arriving at BMC, Rockburne already had a solid education in painting. While she was an elementary student, she won a merit scholarship to the Ecole des BeauxArts in Montreal, for Saturday classes. Rockburne always had a deep respect and fascination with nature. She recalls 
this wonder for nature being sparked one day during an outdoor painting class on Mount Royal, in Montreal:

\begin{abstract}
Although my teacher praised my painting, as I stood and looked first at my work and then at the landscape, I observed and questioned, "Nature does it better. How?" More specifically, I asked myself, what are nature's organizing principles? These questions probably arose because of my father's Algonquin traditions: "Nature is sacred and should be understood, not violated." This moment of inquiry would later directly lead to my ongoing passion for mathematics as the basis for the understanding of nature.
\end{abstract}

During high school, Rockburne won another scholarship to take classes at the Montreal Museum School. Gordon Webber introduced Rockburne to artistic theories from the Bauhaus and Russian constructivism. Rockburne recalls that this was "a different kind of art thinking and was a large part of what drew me to BMC."

In her first week at BMC, Rockburne tried taking a mathematics class with Dehn, but quickly found she was not prepared and dropped out. She says that Dehn must have seen something in her mathematical abilities, because a few days later he offered to teach her mathematics as it is seen in nature. He suggested that she accompany him on his morning hike. Rockburne was greatly influenced by her time with Dehn and this would ultimately shape her career as an artist. Rockburne fondly recalls her time with Dehn:

Dehn considered my lack of math instruction an advantage. I wasn't mathphobic, and, as he so happily put it, I hadn't been poisoned. Dehn had a lively, disciplined, but fearless mind. His enthusiasm for everything was infectious. When I told him I was having some difficulties with assignments, he said, "What you need is to understand the principles of math as they occur in nature. Why don't you join me every day on my early morning hike, and I will teach you mathematics for artists through nature?"

In Dehn Rockburne found a man who, like her father, had a great respect for nature, someone who understood
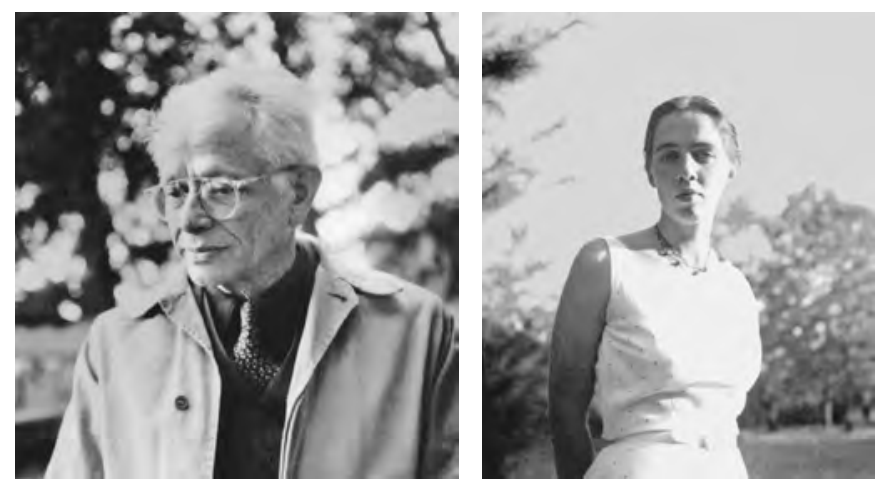

Figure 2. Max Dehn greatly influenced Dorothea Rockburne (1952) at Black Mountain College. nature and who would show her how mathematics could be used to unlock its guiding principles. She recalls a steep hike, about a mile uphill behind the Dehns' home, where they walked to a small waterfall. Dehn discussed the golden ratio and "showed [her] that every kind of growth has recognizable mathematical properties." Dehn recommended that she read several books, including Science and Method by Henri Poincaré, The Laws of Thought by Henry Parker Manning, The Fourth Dimension by C. Howard Hilton, and Flatland by Edwin A. Abbott. In later years, Rockburne would go back to these books for inspiration.

During Rockburne's second year at BMC, Dehn passed away. Rockburne married Carroll Williams, an apprentice teacher and former student at BMC. She participated in John Cage's Theatre Piece No.

1, sometimes called "The First Happening." She attended the international pottery seminar lead by the Japanese potter Shoji Hamada. She danced with Merce Cunningham. In 1954, the family moved to Manhattan. Unfortunately, the marriage did not last long. Soon Rockburne was a young single mother working hard to bring up her daughter in New York City.

Rockburne stayed in touch with many BMC artists, students, and faculty who had moved to the New York area. Encouraged by her BMC friends, in 1957 Rockburne had an exhibition of her work at the Nonagon Gallery in New York. The show got good reviews and she sold several works. Rockburne herself was encouraged, but she felt she needed more time to develop. She recalls, "I knew that these paintings did not emotionally or creatively correspond to my inner need or voice. ... I returned to my studio for ten years to work, study, and form a voice." By keeping her expenses low, she managed to support herself and care for her daughter. For a short while she worked at the Metropolitan Museum of Art and assisted in cataloguing the museum's collection of Egyptian antiquities. Most of the time she worked as a waitress. "To stay sane," she went back and reread the books that Dehn had suggested. She also began her own investigations into mathematics such as reading books on non-Euclidean geometry and set theory. She was not afraid to pick up a real mathematics text to see what she could get out of it. She read these books with the goal to "use them as a learning foundation from which to conceive art." She was fascinated with the history of mathematics and said, "By understanding the history of mathematics, I learned of an exquisite emotional beauty of thought. This in turn gave me greater access to an understanding of a more universal creative process...." Dehn had always stressed the importance of history. If Dehn had talked with Rockburne about hyperbolic geometry, which he used 


\section{Max Dehn}

Max Dehn received his doctorate under David Hilbert in Göttingen in 1900, the same year that Hilbert gave his famous lecture outlining 23 problems for the twentieth century. The next year Dehn was the first to solve one of the problems on Hilbert's list. He solved the third problem, showing that the Archimedean axiom is logically needed to prove that tetrahedra of equal base and height have equal volume. Dehn went on to do ground-breaking work in topology and the theory of infinite groups. In 1907, Dehn coauthored with Poul Heegaard the first comprehensive articles on topology, including the first complete proof of the classification of 2-manifolds. Dehn's work on 3-manifolds included inventing a way to construct new 3-manifolds from existing ones. This process is now called Dehn surgery and is still important in topology today. Dehn used his surgery to construct an infinite set of examples of Poincaré homology spheres. Before this, only Poincaré's single example was known. Dehn was the first to formulate the word and conjugacy problems for finitely presented groups. In an amazing paper from 1911, using hyperbolic geometry, Dehn was able to solve these problems for surface groups. The word and conjugacy problems have continued to play an important role in the study of infinite group theory through present day. In a 1914 paper, Dehn was the first to prove that the right and left trefoil knots are not equivalent. Later in his career he worked on the mapping class groups, finding a finite set of generators now known as Dehn twists. Dehn was an intuitive geometer at heart. Many of the mathematical ideas attributed to him, such as Dehn diagrams, Dehn surgery, and Dehn twists, are in fact simple diagrams that are easy to visualize. Their beauty is that these simple diagrams provide a way to understand more general and complicated situations.

Dehn seems to have been admired and respected by everyone he met. He had grown up with an interest in the arts and music as well as science and mathematics. He learned to read and speak several languages, including Greek, Latin, French, Norwegian, and English. He had a lifelong interest in philosophy, in particular, ancient Greek and modern German philosophy. He had a great

so frequently in his work, or if he talked to her about his views on set theory, axiomatic geometry, topology, and the general abstraction of mathematics, details are lost to time. It seems clear that at least Dehn had sparked her interest in some of these ideas. In particular, as a combinatorial topologist, he could not have helped but to provide her with some of his insights concerning the shape of space.

In the early 1970s Rockburne did a series of works based on her reading of Cantor and set theory, which propelled her into the forefront of the art world. These works, including "Set," "Intersection," and "Null Set," were shown in her first two solo exhibits, as well as group exhibitions in New York, Minneapolis, and Eindhoven in The Netherlands. The Museum of Modern Art purchased

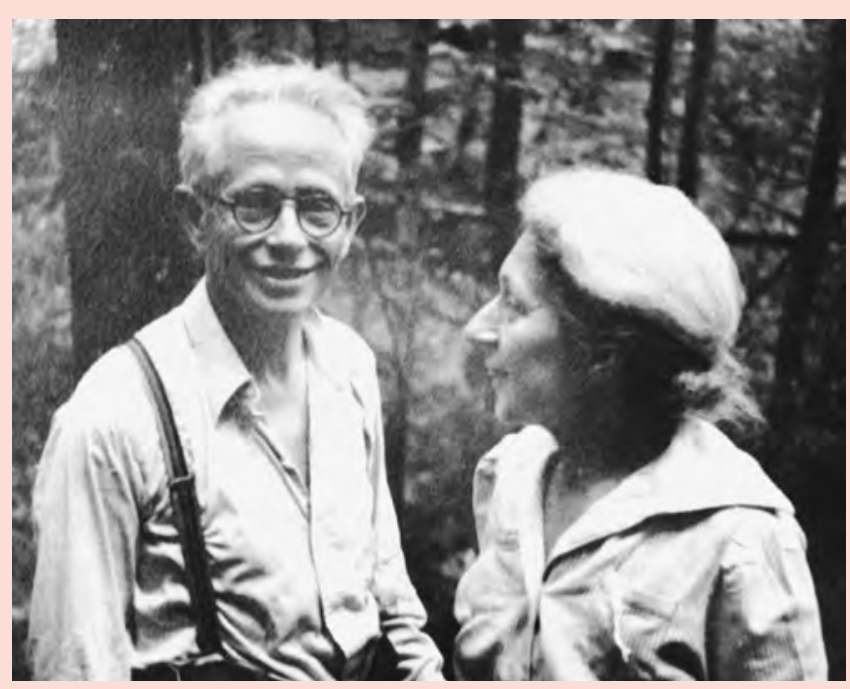

After escaping the Nazis, Max and his wife Toni Dehn eventually settled at BMC in the mountains of North Carolina.

love for hiking and during his life developed an extensive knowledge of botany and the flora of the forest. He had, what we would call today, an interdisciplinary approach. André Weil, in his autobiography, The Apprenticeship of a Mathematician, compared Max Dehn to Socrates and said, "...for such a man, truth is all one, and mathematics is but one of the mirrors in which it is reflected. ... [Dehn was a] humanistic mathematician, who saw mathematics as one chapter-certainly not the least important-in the history of the human mind."

Dehn had been forced by the Nazis to leave his position at the University of Frankfurt in 1935. Three years later, he was arrested the day after Kristallnacht. Dehn and his wife went into hiding and eventually escaped to Norway, where Dehn took a position at the Technical University in Trondheim. After the Germans invaded Norway, the Dehns again had to go into hiding and eventually escaped to Sweden. There they began their long travels to the US through Siberia and Japan and across the Pacific until eventually settling at BMC. ${ }^{1}$

“A, C and D (from Group/And)," a wall-size installation of paper and chipboard with natural pigments, rolled out on the wall and floor, and held together by nails. In March of 1972, Artforum featured her work "Domain of The Variable," on its cover and included an article and an interview with Rockburne.

Rockburne's earliest works were identified with the minimalists. The 1971 work "Scalar" (Figure 3) is inspired by her study of linear algebra. It is made of several 30"x40" sheets of chipboard that had been saturated in crude oil, stacked in her loft, and then left to sit for a summer. These sheets were then attached to the wall by nails in an over-

\footnotetext{
${ }^{1}$ See the 2002 Notices article on "Max Dehn, Kurt Gödel, and the Trans-Siberian Escape Route"www . ams .org/notices/200209/ fea-dawson.pdf.
} 


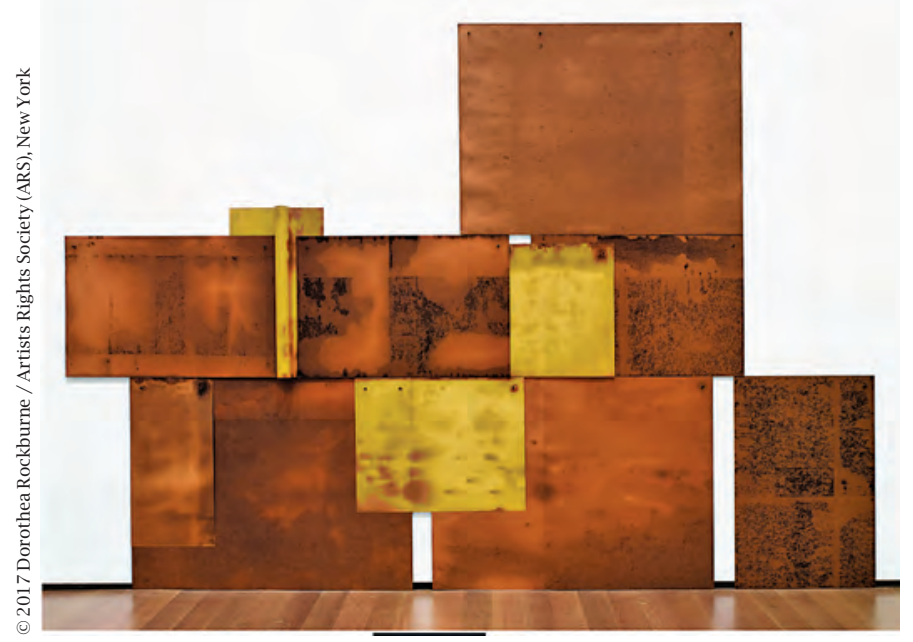

Figure 3. Rockburne's 1971 "Scalar," inspired by linear algebra, had an intriguing three-dimensional aspect. Museum of Modern Art.

lapping array. The whole work measures approximately 10 'x6'. In the art world, it is praised as an early example of experimentation with materials. Rockburne says she used crude oil because she was poor at the time and couldn't afford paints. What she really loved about the oil was how it worked its way through the board and how the image on one sheet was superimposed on the sheets above and below. It was this three-dimensional aspect that intrigued her. By sitting for a summer, the oil had transformed the sheets. Since the sheets had been stacked, they showed a dynamic of this slow transformation of oil soaking down through the sheets and imprinting on each other. The placement of the sheets on the wall provides the viewer with Rockburne's interpretation of this dynamic system.

Rockburne became good friends with Sol LeWitt and other minimalists. She had several works in group exhibitions featuring minimalist artists. However, from the start, Rockburne did not feel that her art fit within the framework of minimalism. "Like them, my work was not decorative nor did I make decisions for aesthetic reasons. My art-making decisions were based on the principles of topology, a complex study of continuous space. ... This is a different spatial concept from the minimalist practice of working on a flat grid." Rockburne had studied the ways in which artists throughout history created space in their works. She had studied ancient Egyptian art, where small fragments can contain incredibly large scale. Early on she had learned of the Renaissance artists and their use of geometry, vanishing points, and the golden mean. She understood the significance of the rebellious Dada artists and how these ideas, mixed with Freud's theories of the subconscious, went on to influence surrealism and abstract expressionism giving a more dreamlike sense of space. Rockburne understood how the cubists had defined a new fragmented canvas that allowed for views from varying angles and staggered moments of time. With her work, she wanted to define a new way to view space that incorporated and drew from these past perspectives, but also would go beyond to new dimensions.
Rockburne's 1973 “Drawing Which Makes Itself: Neighborhood" (Figure 4) is a wonderful example of her ideas to change the way space and time are viewed in a work of art. This work consists of a large rectangular sheet of translucent vellum that has creases folded from corner to corner. This is placed horizontally at the exact center of the wall. There are several lines drawn with different sized colored pencils scattered on the wall around and underneath the vellum. These lines clearly indicate the position of the vellum if it were carefully folded and unfolded to move geometrically along the wall. While the placement of the lines seems to follows some mathematical laws, their position does not look symmetric or mechanical. The color and size of the lines seems to indicate a rhythm and passing of time. Standing back, one can almost see the sheet of vellum beautifully dancing across the wall and leaving only a trace of its passing.

Rockburne's use of lines on the wall around the vellum clearly indicate a break from the tradition of drawing and painting made on a rectangular flat surface. Her works move across the wall and roll out onto the floor. These drawings have broken free of the rectangular frames that hold bounded most other drawings. In this way, her work has opened up a new dimension. It is also interesting to note that in this work she uses translucent vellum. This provides the ability to see through and around the material. Just as in other works where she rolls or folds paper, she is showing both sides of the paper. This gives the viewer a multi-layered perspective.

It is interesting to note what Rockburne means by the title "Neighborhood." As a mathematician, familiar with Rockburne's references to topology, I would be inclined to think of a topological neighborhood. However, this is not the case. The title comes from her reading of Flatland and the mention that one-dimensional Linelanders could never pass each other. Thus, neighborhoods for them are like marriages. This gives an even better insight into Rockburne's thinking. Flatland is about trying to visualize

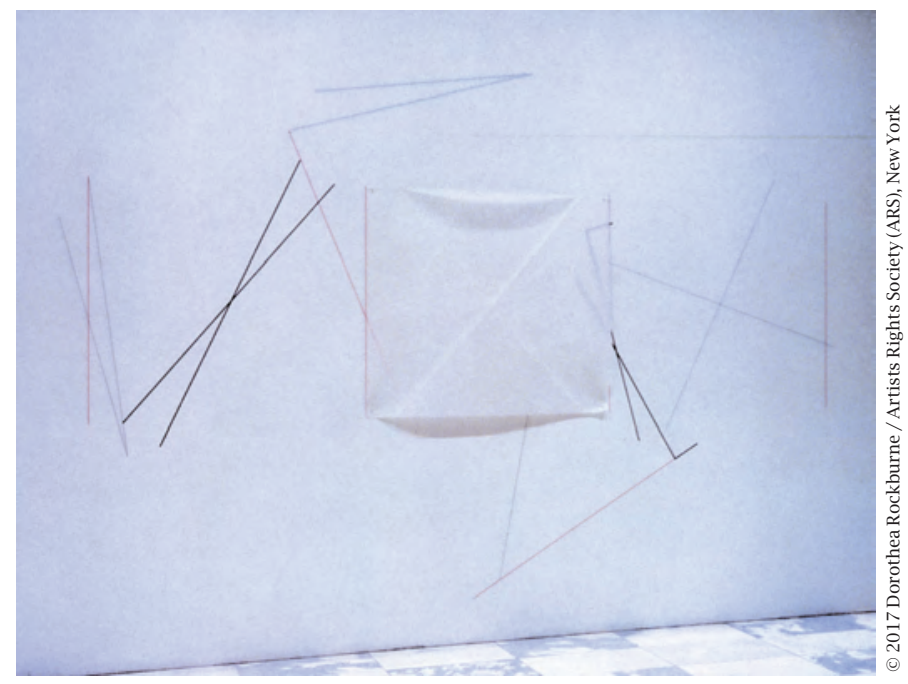

Figure 4. Rockburne's 1973 "Neighborhood" provided a new way to view space and time. Museum of Modern Art. 

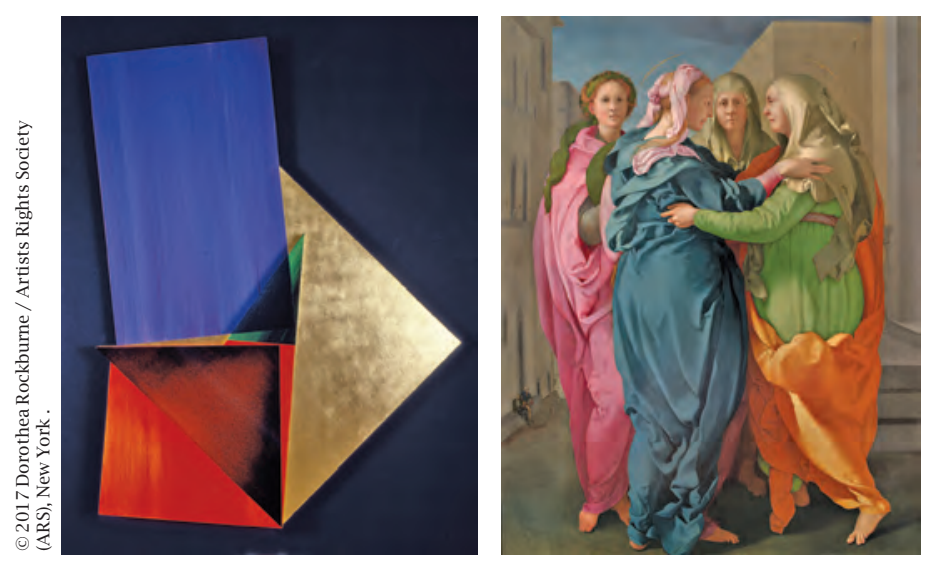

Figure 5. Rockburne's Pascal works, such as "Pascal, State of Grace" (left, 1986-87), were inspired by the philosophy of Blaise Pascal and "Visitation" (right, 1528-29) by Jacopo da Pontormo. Private collection. Pieve di San Michele Arcangelo, Carmignano.

different dimensions, just as Rockburne is trying to do in her work. Also in Flatland women are line segments. Once I made this connection, I could not help but see this work as a woman (a 1-dimensional being), dancing in time through Flatland (a 2-dimensional world), with an order induced by simple mathematical folds, translations and rotations in space (a 3-dimensional universe). The analogy goes even further if you consider that Abbot's book is a satire on 19th century society. The women in Flatland are line segments and thus at the bottom of the social stratus, whereas, in 1970 Rockburne is a woman struggling to be part of a male-dominated profession. This work becomes a self-portrait. Whatever Rockburne intended us to feel and think when we see this work, there is no question that she is extending the way in which space and time are represented in paintings and drawings.

Art historians have found it is hard to classify Rockburne's work. This is partly because, in her 50-year career, she has never stayed with one style. Her earliest work is almost monochromatic. Her later work is full of rich colors, including deep blues and bright golds inspired by her study of Renaissance paintings. She has paintings that measure as small as 4"x6" and others that cover walls over 40 feet high. She has painted on chipboard, paper, vellum, parchment, and copper. Her painting techniques include classic styles of oil painting and frescoes, but also include unique applications of watercolors or crude oil. In general art historians call her a post-modern painter.

In 1988, Rockburne first showed her "Pascal" works (Figure 5), inspired by the philosophy of Blaise Pascal. Here she uses stretched canvas on rectangular (usually golden rectangles) and triangular frames. These are then overlapped to create a painting that is no longer rectangular, but polygonal. The canvases are painted to suggest overlapping and transparency, in a way that is not always consistent with reality. This causes a kind of folding and turning of space that makes it appear that the paintings are looking back at themselves. She uses deep and brilliant colors in these works, a bold step from her earlier use of natural tones or pure white paper. Many of the deep blues and reds and the gold are borrowed from specific paintings by Renaissance masters. Gold leaf was used in Renaissance paintings because of its wonderful ability to reflect natural light and to a create special brilliance, as in halos. In many of these older works there is subtle geometry in the composition, sometimes from the gestures or lines of sight of people in the paintings. Other times shading and colors create planes and simple geometric shapes. The lines and planes in Rockburne's works are inspired by the subtle geometry in these masterpieces. The 1530 painting "Visitation," by Pontormo, was an inspiration for many of the Pascal works.

Conclusion. In some ways Rockburne's career is completely different from Dehn's. She is an artist and Dehn was a mathematician. Her career was only beginning in 1950 while Dehn's was coming to an end. However, in many ways the lifelong endeavors of these individuals run parallel. Both have shown a deep intuitive sense of geometry. Both have worked to improve the understanding of geometry and space in their own disciplines. Dehn's mathematics shows an astonishing geometric insight. His early works, including his solution to Hilbert's third problem, answered deep philosophic questions about Euclidean geometry. His solution to the word problem for surface groups showed a fundamental connection between group theory and hyperbolic geometry. Dehn's work on three manifolds and knot theory was decades ahead of its time. Dehn's geometric insight has had consequences reaching back to Euclid and forward to recent work in geometric group theory and low dimensional topology.

Rockburne's works show similar geometric insight, but applied to paintings and drawings. Like Dehn, Rockburne is deeply interested in history and realizes the importance of studying the works of the past. Her education was in the classics, as well as the most avant-garde of contemporary art. She has a deep understanding of space, shape, and perspective. She has the mind of a geometer. Her early works in the 1970s were multi-dimensional, using the whole room to communicate with the viewers and draw them into the experience. Her works play with geometric shapes, time, and space in ways that other artists had never done before. It is hard to know exactly what specific mathematical details Rockburne learned from her mentor Max Dehn, almost seventy years ago. However, it is clear that theirs was the meeting of two great geometric minds. 


\section{Black Mountain College}

Opened in 1933 and located in a remote area of the North Carolina mountains near Asheville, Black Mountain College (BMC) was an experimental liberal arts college with an emphasis on the arts. Although BMC only existed for 24 years, the college faculty and students have had a tremendous influence on contemporary painting, dance, music, poetry, ceramics, performance art, and architecture.

The curriculum at Black Mountain College was a mix of John Dewey's philosophy on education and theories from the Bauhaus, a German school of design. The production of art-paintings, theater, writing, weaving, furniture making-served as a central core in the students' education. The college was run under democratic principles with no administration, no grades, and no accreditation. Faculty owned the campus. Decisions were made by consensus. Campus upkeep was done by the community of faculty and students. This included building barns, homes, and at one point, a large Studies Building. In 1933 the BMC founders hired Josef and Anni Albers, who had been teaching at the Bauhaus before it was closed by the Nazis. Partly due to the Albers' influence, the college soon began to attract refugee painters, composers, and other artists from Germany and across Europe. Over the years, the college became a magnet for avant-garde European and American artists. The list of distinguished painters who were faculty or students at BMC includes African-American Jacob Lawrence, Willem de Kooning and Robert Motherwell of the "New York School," and pre-pop artist Robert Rauschenberg. A sample of artists from other disciplines includes composer-choreographer duo John Cage and Merce Cunningham, sculptors Ruth

\section{References}

1) M.E. HARRIS, The Arts at Black Mountain College, The MIT Press, Cambridge MA, 1987.

2) A. G. Longwell, Dorothea Rockburne: In My Mind's Eye, The Parrish Art Museum, Southampton, NY, Distributed Art Publishers, New York, NY, 2011.

3) R. B. SHER, Max Dehn and Black Mountain College, Math. Intell., 16 (1994).

\section{Image Credits}

Figures 1, 3, 4, and 5 (left) courtesy of Dorothea Rockburne.

Figure 2 (left by Trude Guermonprez; right by Marie Tavroges Stilkind) courtesy of the Western Regional Archives, State Archives of North Carolina.

Figure 5 (right) "Visitation" from Scala / Art Resource, NY.

Photo of Max and Toni Dehn by Trude Guermonprez, courtesy of the Western Regional Archives, State Archives of North Carolina.

Photo of BMC Studies Building by Hazel Larsen Archer, "The Path to the Studies Building, Black Mountain College," ca. late 1940s-early 1950s, courtesy of Estate of Hazel Larsen Archer and Black Mountain College Museum + Arts Center.

Author photo by Brenda Carleton.

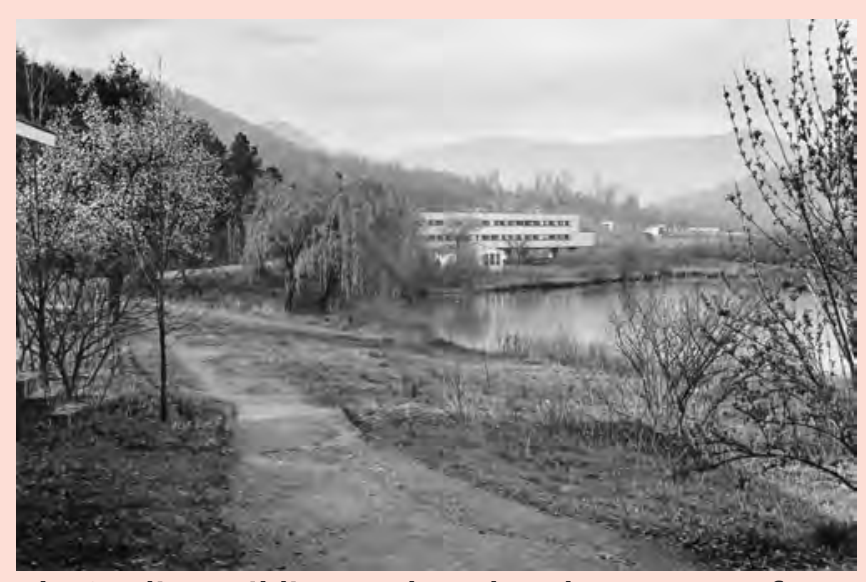

The Studies Building on the Lake Eden campus of Black Mountain College.

Asawa and Kenneth Snelson, and poets Robert Creeley and M. C. (Mary Caroline) Richards.

The campus also attracted notable faculty in the sciences. Both Nathan Rosen and Peter Bergmann taught at BMC for a year after doing postdoctorial work with Albert Einstein.

Einstein visited the campus one day in 1941 and remained an "honorary member" of the advisory board for several years. Natasha Goldowski Renner, a metallurgist, had been one of the top-ranking woman in the Manhattan Project before teaching at BMC for six years. In 1949, Buckminster Fuller built his first successful geodesic dome on the campus.

Two of Dehn's BMC students went on to get PhDs in mathematics and statistics. Several mathematicians visited Dehn at BMC, including Emil Artin, Wilhelm Magnus, Carl Siegel, and André Weil.

\section{ABOUT THE AUTHOR}

David Peifer has been a board member at the Black Mountain College Museum and Art Center for the past nine years. He enjoys hiking and mountain biking with his family and friends.

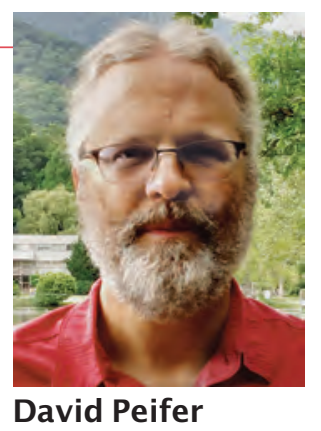

